\title{
AVALIAÇÃO SENSORIAL E DETERMINAÇÃO DE VIDA-DE-PRATELEIRA DE MAÇÃS DESIDRATADAS ${ }^{1}$
}

\author{
Andressa Regina VASQUES ${ }^{2}$, Sávio Leandro BERTOLI², \\ Rita de Cássia Siqueira Curto VALLE², José Alexandre Borges VALLE ${ }^{2, *}$
}

\begin{abstract}
RESUMO
O objetivo deste trabalho foi determinar a preferência sensorial e vida-de-prateleira de fatias de maçãs das cultivares Fuji e Gala desidratadas. A secagem foi feita à temperatura de $60{ }^{\circ} \mathrm{C}$, com velocidade do ar no interior do secador de bandejas de $0,121 \mathrm{~m} / \mathrm{s}$. Para a realização do teste de preferência sensorial e aceitabilidade, mediante uso de uma escala de avaliação, foram utilizadas as maçãs com e sem pré-tratamento, obtendo-se um total de 4 amostras para análise. A maçã com maior índice de aceitação foi a maçã da cultivar Fuji sem tratamento, e a maçã com índice elevado de rejeição foi a maçã Gala sem tratamento, com $25 \%$. De acordo com o resultado da análise sensorial, a vida-de-prateleira experimental das maçãs desidratadas foi determinada para as maçãs Fuji sem pré-tratamento e para as maçãs Gala com tratamento em diferentes tipos e tamanhos de embalagens. Em 360 dias de armazenamento, à temperatura ambiente, observou-se principalmente o significativo aumento do ganho de umidade nas maçãs de ambas as cultivares em embalagens de Polietileno Tereftalato e Copolímero de Cloreto de Vinil e Vinilideno/ Polietileno (Pet Saran/Pe) e não se observou diferenças significativas entre as embalagens de Polietileno Tereftalato/Alumínio/Polietileno (Pet/Al/Pe) e Polipropileno/Alumínio/ Polietileno (PP/Al/Pe).
\end{abstract}

Palavras-chave: Maçãs Fuji e Gala desidratadas, análise sensorial, vida-de-prateleira, embalagem.

\section{SUMMARY}

SENSORIAL EVALUATION AND DETERMINATION OF DEHYDRATED APPLE SHELF LIFE. The objective of this work was to determine the sensorial preference and the shelf live of dehydrated Fuji and Gala culture apple slices. Drying was done at a temperature of $60{ }^{\circ} \mathrm{C}$ and at an air speed of $0.121 \mathrm{~m} / \mathrm{s}$ inside the tray dryer. In order to carry out the sensorial preference and acceptability test with the use of an evaluation scale, apples with and without pretreatment were used, resulting in a total of 4 samples for analysis. The apple with the greatest acceptance was the Fuji and the culture apple with a high rejection rate was the Gala without pretreatment, represented by $25 \%$ of the 100 people who tasted it. According to the sensorial analysis result, the experimental shelf life of the dehydrated apples was determined for Fuji apples without pretreatment and for Gala ones with pretreatment in different packaging types and sizes. In 360 days, in room temperature, a significant increase in the humidity of the apples of both cultures packed in Pet Saran/ Polyethylene was observed while no significant differences were noted with the Polyethylene Terephthalate/Aluminum/Polyethylene and Polypropylene/ Aluminum/Polyethylene packaging.

Keywords: Dehydrated Fuji and Gala apples; sensorial analysis, shelf life, packing.

\section{1 - INTRODUÇÃO}

O Brasil destaca-se como um dos maiores produtores mundiais de frutas. Os Estados do Rio Grande do Sul e Santa Catarina participam como grandes produtores de frutas de clima temperado, tendo a maçã como principal representante, alcançando uma produção de mais de 1 milhão de toneladas para a safra de 2004.

A maçã produzida no Brasil, que apresenta uma característica de sabor diferenciada em relação à importada, mudou os hábitos do consumidor brasileiro, resultando em um consumo anual per capta em 2004, de 3,5 a 4,3 kg.

No Brasil, a capacidade de armazenamento de maçãs é de 511.525 t, cerca de $60 \%$ da produção nacional, sendo $44 \%$ do volume armazenado em câmaras frias com atmosfera controlada. O Estado de Santa Catarina apresenta maior

\footnotetext{
${ }^{1}$ Recebido para publicação em 29/7/2005. Aceito para publicação em 20/10/2006 (001581)

2Depto. de Engenharia Química (FURB), Rua São Paulo, 3250,

CEP 89030-000 Blumenau (SC), Brasil,

E-mails: andressavasques@terra.com.br; sávio@furb.br; ritav@furb.br; alex@furb.br

* A quem a correspondência deve ser enviada
}

capacidade de armazenamento total e maior proporção em atmosfera controlada [3].

As principais cultivares de maçãs produzidas no Brasil são a Gala e a Fuji, além de suas mutações. Toda a colheita ocorre nos primeiros 4 meses do ano. O ponto de colheita está relacionado com determinados índices ou parâmetros e alguns desses (geração de $\mathrm{CO}_{2}$ pela respiração, amido, acidez titulável, açúcares, firmeza de polpa, etc.) são utilizados para estabelecer critérios mínimos e máximos aceitáveis, de acordo com o destino da fruta já colhida.

A colheita de maçãs no momento ótimo implica em diminuir a possibilidade de ocorrência de perdas durante o armazenamento e a comercialização, por conta das desordens fisiológicas próprias de frutas imaturas ou muito maduras. As frutas colhidas antes de completado o seu desenvolvimento têm seu processo de amadurecimento comprometido, não alcançando a qualidade desejada para o consumo, comprometendo o sabor e o aroma e desidratando-se com maior facilidade. Por sua vez, as frutas colhidas em estágios de maturação avançados são mais susceptíveis a danos mecânicos, ataque de patógenos e insetos, como também 
a distúrbios fisiológicos do tipo "bitter pit" (manchas de cortiça superficial), depressão lenticelar, etc. [4, 6].

Além da preservação em atmosfera controlada, a desidratação está sendo muito utilizada para aumentar a vida de prateleira de diversas frutas e vegetais pela redução da sua atividade de água, diminuindo o volume de armazenamento e facilitando o transporte. Mas o processo de desidratação não se trata somente da retirada de água de um alimento. Para que seja obtido um alimento desidratado, há necessidade de se preparar o alimento previamente ao processo, por meio de lavagem, corte, branqueamento e outras etapas, que podem, juntamente com a secagem propriamente dita, ser responsáveis por determinadas reações de deteriorizações de qualidade, como reações de oxidação [2].

A qualidade de produtos alimentícios se altera com o tempo de estocagem pela ocorrência de uma série de transformações bioquímicas e microbiológicas. No caso de alimentos de atividade de água baixa, conhecidos como alimentos sensíveis à umidade, essa perda de qualidade e a conseqüente limitação da sua vida-de-prateleira estão geralmente associadas ao fenômeno de ganho de umidade, que leva a alterações como a aglomeração (produtos em pó) ou a alteração na textura (biscoitos) [1]. A vida-de-prateleira desses produtos depende, fundamentalmente, da proteção oferecida pela embalagem contra a adsorção de umidade disponível no ambiente de estocagem. Para um produto desidratado, a função da embalagem, no caso, é de minimizar ou impedir a passagem do vapor d'água para o seu interior, evitando, dessa forma, que a atividade de água do produto atinja níveis que possibilitem o desenvolvimento microbiano [2].

A especificação de embalagens para os produtos sensíveis à umidade requer prévio conhecimento do nível de proteção oferecido pelos materiais da embalagem, sendo que o método tradicional para esta avaliação consiste do acondicionamento do produto nas embalagens, estocagem em condições controladas e análises periódicas para avaliação da deterioração do produto e/ou aceitabilidade organoléptica [6].

A embalagem flexível para produtos alimentícios desidratados limita o seu contato com o oxigênio atmosférico e o seu ganho de umidade. As transferências de oxigênio e umidade são simultâneas, sendo que, quando o ganho de umidade for mais importante do que a transferência de oxigênio, o produto poderá deteriorar-se devido ao ganho de umidade, antes que as reações oxidativas o tornem impróprio para consumo [2, 9].

Fatores complexos influenciam a aceitação de alimentos pelo consumidor. É difícil determinar até que ponto as propriedades sensoriais modificam a seleção e utilização de um alimento, visto que todos estes fatores interagem e influenciam as decisões do consumidor. Inicialmente a aparência externa é provavelmente o atributo de qualidade que determina o valor comercial do produto. No caso de maçãs, a característica cor é um dos principais fatores de aceitação pelo consumidor, já que as características visuais controlam a seleção do alimento.
O desenvolvimento de novos produtos acentua a necessidade de testes seguros, eficientes e representativos da opinião do consumidor, tanto quanto o estudo contínuo das mudanças nos hábitos alimentares. Os testes de preferência e aceitação com equipes de consumidores são indicados para avaliar, em termos de qualidade hedônica e aceitação, novos produtos lançados no comércio [11].

Com o objetivo de determinar a preferência sensorial e vida-de-prateleira de fatias de maçãs desidratadas, fez-se uma análise sensorial com 100 consumidores não treinados e, a partir do resultado da análise, foram escolhidas as maçãs desidratadas das cultivares Fuji sem pré-tratamento e Gala com pré-tratamento para a determinação da vida-de-prateleira experimental, levando-se em consideração somente o ganho de umidade. As amostras foram armazenadas em embalagens de Pet Saran/Pe, Pet/Al/Pe e PP/Al/Pe de capacidade de 32 e 70 g de maçãs desidratadas.

\section{2 - MATERIAL E MÉTODOS}

\section{1 - Maçãs}

As maçãs "in natura" das cultivares Gala e Fuji foram adquiridas no Ceasa da cidade de Blumenau/SC e armazenadas à temperatura de $8{ }^{\circ} \mathrm{C}$ e foram usadas de acordo com a necessidade experimental.

\section{2 - Desidratação}

Processamento da matéria-prima. As maçãs foram cortadas ao meio, tiveram suas sementes retiradas e foram fatiadas com aproximadamente $4 \mathrm{~mm}$ de espessura. Para a realização do teste de preferência sensorial foram utilizadas maçãs das cultivares Fuji e Gala com e sem pré-tratamento. Para o pré-tratamento feito, utilizou-se solução de bissulfito de sódio (5,6 g/L de água), para evitar a oxidação, e de amido pré-gelatinizado (20 g/L dissolvido em água a $70{ }^{\circ} \mathrm{C}$ ), a fim de melhorar a crocância das fatias. De acordo com a preferência sensorial, o teste de vida-de-prateleira foi realizado para as maçãs Fuji (as quais não passaram por pré-tratamento antes de serem desidratadas) e para as maçãs Gala, as quais foram submetidas ao pré-tratamento.

As fatias de maçã foram desidratadas em um secador de bandejas com controle microprocessado de temperatura e controle de velocidade de rotação do ventilador, por um potenciômetro.

Psicrômetro foi utilizado para determinação da umidade relativa média do ar ambiente nos dias em que se realizaram as secagens.

Processo de secagem. A secagem das maçãs Fuji e Gala com e sem pré-tratamento para análise sensorial, foi realizada em um único dia e as maçãs desidratadas foram armazenadas em potes plásticos com a numeração específica para o teste de preferência. A temperatura do ar de secagem foi de $60{ }^{\circ} \mathrm{C}$ e a velocidade do ar de secagem foi de $0,121 \mathrm{~m} / \mathrm{s}$. As secagens das maçãs das cultivares Gala e Fuji para o 
teste experimental de vida-de-prateleira foram realizadas em 3 dias consecutivos. As mesmas condições de secagem foram mantidas para o teste de preferência sensorial e teste de vida-de-prateleira experimental.

\section{3 - Análise sensorial}

A avaliação sensorial constituiu-se de um teste de preferência e aceitabilidade realizada com uma equipe não treinada de 100 consumidores de diferentes idades e classes sociais que compõem a comunidade universitária (Blumenau/ SC-Brasil). O projeto deste trabalho foi aprovado pelo Comitê de Ética na Pesquisa em Seres Humanos segundo Conselho Nacional de Saúde (Resolução CNS 196/1996).

As amostras foram servidas aleatoriamente aos julgadores em copos plásticos, com quantidades padronizadas (aproximadamente 2 g - 3 fatias), e codificados com 3 dígitos. Foi fornecida água para limpeza do palato entre a avaliação das amostras. O teste foi realizado em local reservado, e os provadores receberam orientação anterior ao teste.

Avaliou-se a aceitação geral utilizando-se uma escala hedônica de 1 a 9 pontos, em que o ponto 1 correspondia a "eu comeria isto, em cada oportunidade que tivesse" e o ponto 9 a "eu comeria isto, se fosse forçado". A preferência e a aceitação foram obtidas mediante uso de uma escala de avaliação estruturada com nove pontos, com o propósito de quantificar um atributo estritamente psicológico. Esta escala foi utilizada, pois requer menor tempo para avaliação, apresenta procedimentos muito interessantes para o provador, e pode ser utilizada por provadores não treinados e com um elevado número de estímulos [7, 12 e 13].

\section{4 - Vida-de-prateleira experimental}

A qualidade de frutas e hortaliças desidratadas se altera com o tempo de estocagem devido à ocorrência de reações como a atividade microbiana, oxidação e degradação de pigmentos, escurecimento não-enzímico e oxidação de vitaminas. Mas, basicamente, esses produtos, quando embalados, podem apresentar um maior período de vida-de-prateleira se protegidos para evitar o contato com o oxigênio e o ganho de umidade. A vida-de-prateleira depende, fundamentalmente, da proteção oferecida pela embalagem contra a absorção de umidade disponível no ambiente de estocagem [10]. Para os resultados obtidos para a vida-de-prateleira, foi aplicado o teste estatístico ANOVA para verificar se houve ou não diferenças significativas quanto aos grupos analisados ou, quando necessário, aplicou-se o Teste de Tukey (5\% de significância) para verificar se houve ou não diferenças significativas quanto aos pares de amostras.

Análises físico-químicas. Foram realizadas análises físico-químicas a fim de caracterizar a matéria-prima antes da secagem, comparando os resultados obtidos com a literatura [6]. As seguintes análises foram feitas de acordo com a metodologia apresentada pelas Normas Analíticas do Instituto Adolfo Lutz [8]: pH, Sólidos Solúveis Totais (SST), Acidez Total Titulável (ATT), firmeza de polpa e amido. O volume gasto na titulação para determinação da ATT representa a acidez expressa em meq/100 mL e os índices de amido variam de 1 a 5, sendo que o valor 1 na escala corresponde a frutas totalmente verdes, nas quais não ocorreu degradação do amido, e o valor 5 corresponde a frutas com maturação avançada sem presença de amido.

Tempo médio de secagem. Na determinação do tempo de secagem médio em cada dia, considerou-se que a primeira bandeja a ser colocada na desidratadora foi a primeira a ser retirada, de forma que todas as bandejas permaneceram na desidratadora por tempos iguais. A média dos tempos de secagem foi feita de forma aritmética, obtendo assim, ao final do processamento, um tempo mínimo de secagem e um tempo máximo de secagem.

Durante a secagem, as bandejas foram trocadas de posição no desidratador, com vistas a obter melhor homogeneização das fatias de maçãs desidratadas. Esta troca de lugares foi feita levando-se em conta o aspecto visual.

Média da quantidade de fatias por embalagem e média da massa de cada fatia desidratada. Após a secagem, as fatias foram embaladas. Foi feita uma contagem das fatias para cada embalagem de 32 g e obtida a massa média aritmética de cada fatia por embalagem.

Embalagens. As embalagens utilizadas para o armazenamento das fatias de maçãs desidratadas são apresentadas na Tabela 1 .

TABELA 1 - Diferentes embalagens utilizadas para o armazenamento das maçãs desidratadas.

\begin{tabular}{|c|c|c|c|}
\hline & $\mathrm{Pet}^{1} / \mathrm{Al}^{2} / \mathrm{Pe}^{3}$ & Pet Saran $4 / \mathrm{Pe}$ & $\mathrm{PP}^{5} / \mathrm{Al} / \mathrm{Pe}$ \\
\hline Tamanho 1 (T1) & $15,5 \times 16 \mathrm{~cm}$ & $15,5 \times 16 \mathrm{~cm}$ & $15,5 \times 16 \mathrm{~cm}$ \\
\hline Quantidade & $32 \mathrm{~g}$ & $32 \mathrm{~g}$ & $32 \mathrm{~g}$ \\
\hline Tamanho 2 (T2) & $20 \times 25 \mathrm{~cm}$ & $20 \times 25 \mathrm{~cm}$ & - \\
\hline Quantidade & $70 \mathrm{~g}$ & $70 \mathrm{~g}$ & - \\
\hline $\begin{array}{l}\text { Permeabilidade } \\
\text { ao vapor d'água }\end{array}$ & $0,01 \mathrm{~g} / \mathrm{m}^{2} \mathrm{dia}$ & $3,7 \mathrm{~g} / \mathrm{m}^{2} \mathrm{dia}$ & $0,01 \mathrm{~g} / \mathrm{m}^{2} \mathrm{dia}$ \\
\hline
\end{tabular}

Cloreto de Vinil e Vinilideno; e ${ }^{5}$ Polipropileno.

As embalagens de Polietileno Tereftalato e Copolímero de Cloreto de Vinil e Vinilideno/Polietileno (Pet Saran/Pe); de Polietileno Tereftalato/Alumínio/Polietileno (Pet/Al/Pe) e Polipropileno/Alumínio/Polietileno ( $\mathrm{PP} / \mathrm{Al} / \mathrm{Pe})$ são revestidas internamente por polietileno o que permite a soldagem a quente.

As diferentes embalagens foram avaliadas experimentalmente por meio do ganho de umidade das maçãs desidratadas, determinando-se a umidade das fatias armazenadas ao longo de 360 dias.

A Figura 1 apresenta a metodologia utilizada para avaliar o efeito da embalagem sobre a vida-de-prateleira das maçãs desidratadas.

As ligações entre os diferentes tamanhos e tipos de embalagens, conforme Figura 1, mostram as comparações que foram realizadas entre as amostras. No total foram obtidos 


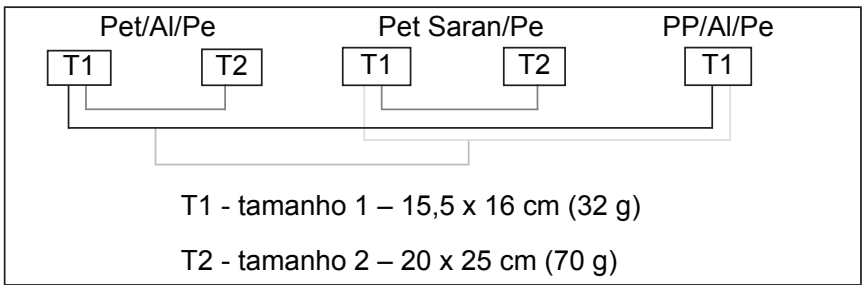

FIGURA 1 - Procedimento de análise experimental.

13 pontos experimentais (medida de ganho de umidade por tempo) para cada tamanho e tipo de embalagem e para cada cultivar (Fuji e Gala).

Ganho de umidade. Para a determinação do ganho de umidade, obtém-se a massa seca do produto "in natura" e do produto desidratado em cada dia de análise. Os resultados de massa seca foram utilizados para obter o teor de umidade em base úmida do material contido na embalagem. Para cada dia de análise foram utilizadas 10 placas de petri mais a repetição de cada uma delas, dando um total de 20 placas. Foram armazenadas 2 amostras, maçã Gala desidratada com pré-tratamento e maçã Fuji desidratada sem pré-tratamento, para cada tipo e tamanho de embalagem (PP/Al/Pe (32 g), Pet/Al/Pe(32 g), Pet Saran/Pe (32 g), Pet/Al/Pe (70 g) e Pet Saran/Pe $(70 \mathrm{~g})$ ). A massa seca do produto embalado foi feita em duplicata permanecendo em temperatura de $102{ }^{\circ} \mathrm{C}$ durante $24 \mathrm{~h}$ e o resultado foi calculado a partir da média aritmética das massas iniciais e finais.

Nas análises, sempre foram inauguradas novas embalagens com maçãs armazenadas conforme datas préestabelecidas. As maçãs foram retiradas para que fossem feitas as análises de ganho de umidade por meio da massa seca do produto. Este resultado foi utilizado para obter o teor de umidade em base úmida do material contido na embalagem.

A análise experimental foi encerrada em 360 dias, sendo feito ensaios de ganho de umidade aos 0, 10, 20, 30, 50, $70,100,130,160,200,240,280,320$ e 360 dias, obtendo-se um total de 14 pontos experimentais apresentados nos resultados.

\section{3 - RESULTADOS E DISCUSSÕES}

\section{1 - Caracterização das maçãs}

Os resultados obtidos da caracterização (análises físico-químicas) das maçãs "in natura" são demonstrados na Tabela 2.
As maçãs que foram utilizadas para as análises físicoquímicas apresentaram resultados coerentes com os parâmetros de colheita apresentados por Girard, Nachtigall, Parussolo [6].

\section{2 - Análise sensorial}

A análise sensorial foi realizada para as fatias desidratadas das cultivares Fuji e Gala com e sem pré-tratamento. Uma equipe não-treinada de 100 consumidores foi consultada por meio da aplicação do Teste de Escala de Ação. Os resultados demonstraram que as fatias de maçãs da cultivar Fuji sem tratamento obtiveram a maior porcentagem de aceitação (86\%) e apenas $3 \%$ comeriam o produto se não tivessem outra escolha, conforme se pode verificar nas Figuras 2 e 3. As fatias da cultivar Gala sem tratamento obtiveram o último lugar na classificação, pois foram rejeitadas por 25 pessoas, como se pode observar nas Figuras 4 e 5 . As cultivares Fuji e Gala com tratamento ficaram com $83 \%$ e $79 \%$ de aprovação, respectivamente.

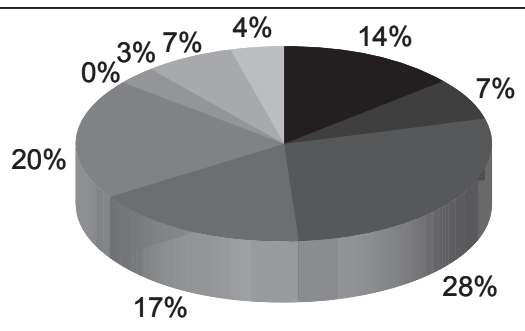

- Eu comeria isto, em cada oportunidade que tivesse

$\square$ Eu comeria isto, muito freqüentemente

- Eu comeria isto, freqüentemente

- Eu comeria isto, agora e depois

- Eu comeria isto se possível, mas não sairia da minha rotina

口 Eu não gosto, mas se fosse preciso, comeria

$\square$ Eu comeria isto, raramente

$\square$ Eu comeria isto, somente se não tivesse outra escolha

$\square$ Eu comeria isto, se fosse forçado

FIGURA 2 - Resultados da avaliação sensorial de fatias de maçãs Fuji desidratadas sem pré-tratamento obtidos da aplicação do teste de escala de ação com 100 consumidores.

Para a Figura 3, a soma das porcentagens foi feita mediante a escala de ação na qual o nível de aceitação da fatia varia entre "Eu comeria, em cada oportunidade que tivesse" até "Eu comeria isto se possível, mas não sairia da minha rotina”, e o nível de não-aceitação da fatia varia entre "Eu

TABELA 2 - Análises Físico-químicas das maçãs "in-natura".

\begin{tabular}{|c|c|c|c|c|c|c|c|}
\hline Cultivar & Amido (índice) & $\mathrm{pH}$ & ${ }^{\circ}$ Brix & $\begin{array}{l}\text { Acidez Total } \\
\text { Titulável } \\
\text { (meq/ } 100 \mathrm{~mL} \text { ) }\end{array}$ & $\begin{array}{c}\text { Firmeza de } \\
\text { polpa } \\
\left(\mathrm{lb} / \mathrm{m}^{2}\right)\end{array}$ & $\begin{array}{l}\text { Média de Sóli- } \\
\text { do seco em \% } \\
\text { (kg de água/kg } \\
\text { de sólido seco) } \\
\text { para maçã sem } \\
\text { tratamento }\end{array}$ & $\begin{array}{l}\text { Média de Sóli- } \\
\text { do seco em \% } \\
\text { (kg de água } / \mathrm{kg} \\
\text { de sólido seco) } \\
\text { para maçã com } \\
\text { tratamento }\end{array}$ \\
\hline Fuji & 2,5 & 3,36 & 12,47 & 7,5 & 17,23 & 15,41 & - \\
\hline Gala & 3 & 3,38 & 11,80 & 8,5 & 13,71 & 13,63 & 12,88 \\
\hline
\end{tabular}


não gosto, mas se fosse preciso, comeria" até "Eu comeria isto, se fosse forçado".

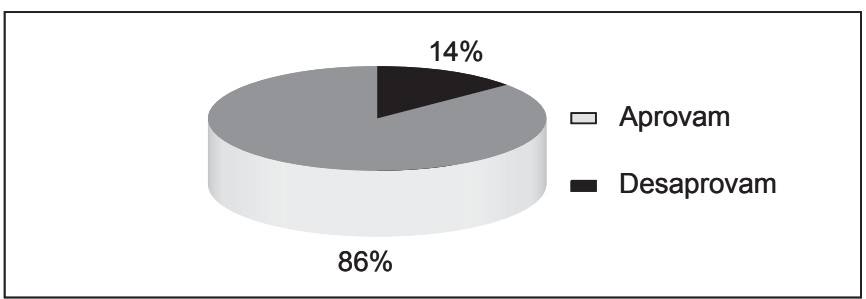

FIGURA 3 - Porcentagem de aceitação das fatias de maçãs Fuji desidratadas sem pré-tratamento obtidos da aplicação do teste de escala de ação com 100 consumidores.

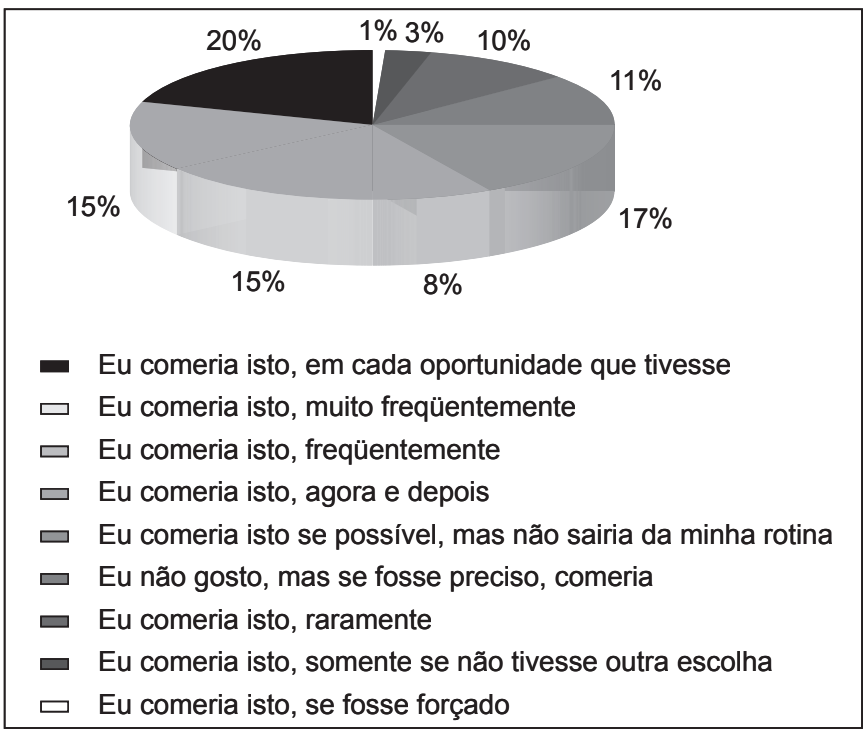

FIGURA 4 - Resultados da avaliação sensorial de fatias de maçãs Gala desidratadas sem pré-tratamento, obtidos do teste de escala de ação com 100 consumidores.

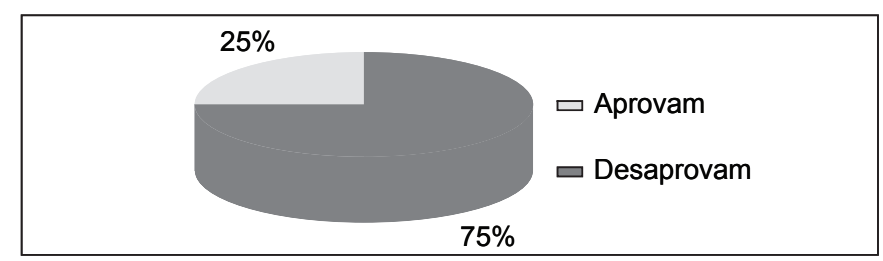

FIGURA 5 - Porcentagem de aceitação das fatias de maçãs Gala desidratadas sem pré-tratamento, obtidos da aplicação do teste de escala de ação com 100 consumidores.

Após a realização do teste, verifica-se que a cultivar Fuji sem pré-tratamento tem maior aceitação do que a com pré-tratamento, e a cultivar Gala com pré-tratamento tem maior aceitação que a Gala sem pré-tratamento. A Fuji sem e a Gala com pré-tratamento foram, então, armazenadas nas embalagens especificadas no item Embalagens, para estimar-se, de maneira experimental, seu tempo de vidade-prateleira com relação ao ganho de umidade.

\section{3 - Vida-de-prateleira}

A Tabela 3 demonstra os resultados obtidos para a Maçã Fuji sem tratamento desidratada e para a Maçã Gala com tratamento desidratada.
TABELA 3 - Resultados da massa média por fatia, a média da massa seca, a umidade relativa média durante os dias de secagem e o tempo médio de secagem para os dias em que as maçãs das cultivares Fuji e Gala foram desidratadas.

\begin{tabular}{lllll}
\hline & $\begin{array}{c}\text { Maçã Fuji sem trata- } \\
\text { mento desidratada }\end{array}$ & $\begin{array}{c}\text { Maçã Gala com trata- } \\
\text { mento desidratada }\end{array}$ \\
\hline Massa média por fatia & \multicolumn{2}{c}{$0,73 \mathrm{~g} /$ fatia } & \multicolumn{2}{c}{$0,60 \mathrm{~g} /$ fatia } \\
Média da Massa Seca & \multicolumn{2}{c}{$93,02 \%$} & \multicolumn{2}{c}{$90,49 \%$} \\
\hline Umidade Relativa & Máximo & $65 \%$ & Máximo & $67,5 \%$ \\
média para os 3 dias & Mínimo & $54 \%$ & Mínimo & $61,5 \%$ \\
de secagem & Média & $60 \%$ & Média & $64,67 \%$ \\
\hline Tempo de secagem & Máximo & $4: 18 \mathrm{~h}$ & Máximo & $6: 03 \mathrm{~h}$ \\
médio para os 3 dias & Mínimo & $4: 05 \mathrm{~h}$ & Mínimo & $5: 11 \mathrm{~h}$ \\
de secagem & Média & $4: 14 \mathrm{~h}$ & Média & $5: 53 \mathrm{~h}$ \\
\hline
\end{tabular}

Os resultados sobre o ganho de umidade são apresentados nas Figuras 6-9; na Figura 10, são apresentadas as médias com desvios-padrão do teor de umidade em base úmida (TBU\%) para as embalagens utilizadas, além disto, as letras iguais apresentadas sobre as barras indicam igualdade entre os tratamentos com nível de significância de $5 \%$, por análise de média de Tukey.

Durante o armazenamento de 360 dias, observaramse diferenças significativas, mediante a aplicação do teste ANOVA, para as embalagens com mesmo valor de permeabilidade ao vapor de água (tamanho pequeno-32 g e lâminas de $\mathrm{PP} / \mathrm{Al} / \mathrm{Pe}$ e Pet/Al/Pe) para as cultivares Gala e Fuji. As duas embalagens com a mesma cultivar não apresentaram diferenças significativas em relação ao ganho de umidade; houve diferença significativa entre a cultivar Fuji armazenada em Pet/Al/Pe e a Gala armazenada em PP/Al/Pe; e, além disto, não houve diferença significativa entre as cultivares em embalagens de Pet/Al/Pe, conforme resultados da aplicação do teste de Tukey (5\% de significância).

O teor de umidade médio (Figura 10) foi maior para a cultivar Gala durante o armazenamento, pois foi armazenada inicialmente com maior teor de umidade (Figura 6), devido ao ponto de parada no processo de secagem.

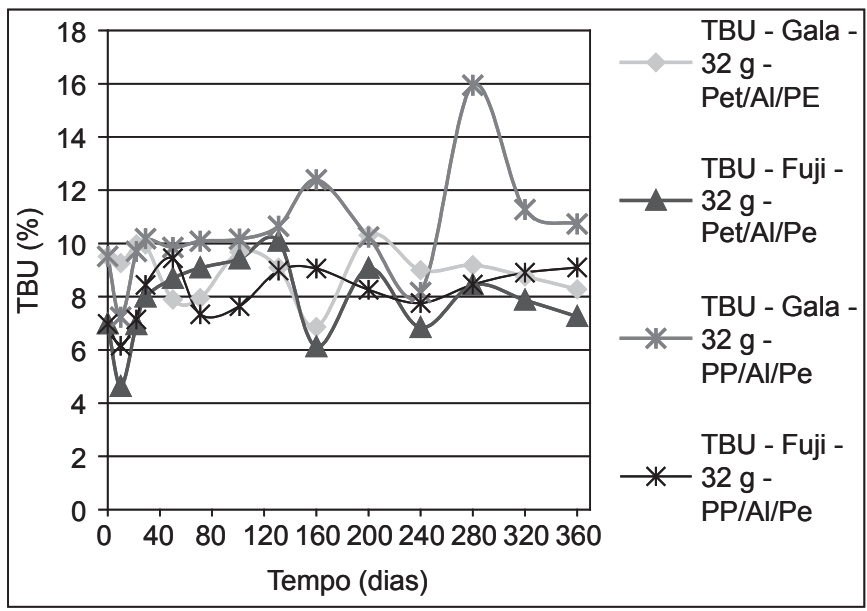

FIGURA 6 - Teor de umidade em base úmida (\%) ao longo do tempo de armazenamento de fatias de maçãs Fuji e Gala desidratadas embaladas em Pet/Al/Pe e PP/Al/Pe de $32 \mathrm{~g}$. 
Observou-se também que houve diferenças significativas entre as 6 amostras armazenadas nas embalagens de $32 \mathrm{~g}$, conforme resultado da aplicação do teste estatístico ANOVA. E mediante a aplicação do teste de Tukey verificou-se que não houve diferença significativa entre as cultivares embaladas em Pet Saran/Pe de 32 g, mas houve diferenças significativas entre as embalagens de Pet Saran/Pe com relação às outras embalagens (PP/Al/Pe e Pet/Al/Pe) de 32 g, com exceção da cultivar Gala armazenada em $\mathrm{PP} / \mathrm{Al} / \mathrm{Pe}$.

Em 360 dias de armazenamento das maçãs desidratadas, não se verificaram diferenças significativas, quanto ao tamanho das embalagens de $\mathrm{Pet} / \mathrm{Al} / \mathrm{Pe}$ para ambas as cultivares, mediante resultado verificado pela aplicação do teste estatístico de Tukey; e o mesmo resultado pôde ser verificado para as embalagens de Pet Saran/Pe (Figuras 7, 8 e 10), pois a massa de maçã desidratada é proporcional ao tamanho das embalagens, tem-se o dobro de massa de maçã para o dobro de tamanho da embalagem.

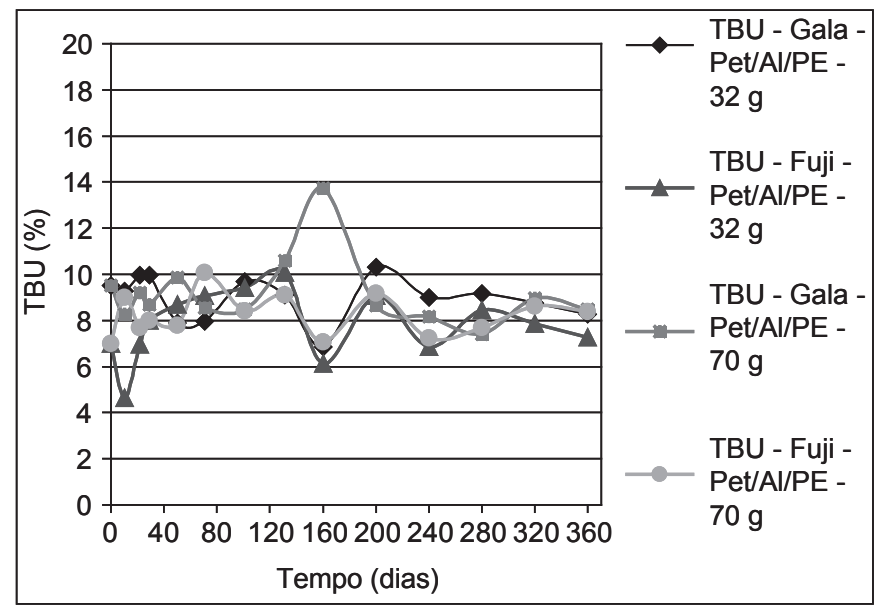

FIGURA 7 - Teor de umidade em base úmida (\%) ao longo do tempo de armazenamento de fatias de maçãs Fuji e Gala desidratadas embaladas em Pet/Al/Pe de 32 e 70 g.

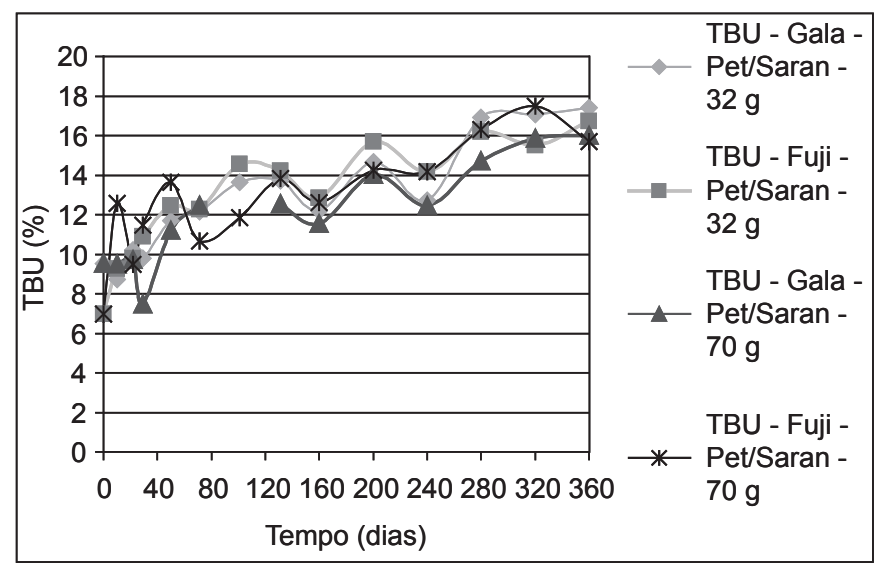

FIGURA 8 - Teor de umidade em base úmida (\%) ao longo do tempo de armazenamento de fatias de maçãs Fuji e Gala desidratadas embaladas em Pet Saran/PE de 32 e $70 \mathrm{~g}$.

O teste de ANOVA também foi aplicado para verificar diferenças significativas para as maçãs armazenadas em embalagens de $70 \mathrm{~g}$ (Pet/Al/Pe e Pet/Saran/Pe) e o resultado indicou diferenças significativas. Também se observou que não existem diferenças significativas entre as cultivares Fuji e Gala para o armazenamento em mesma embalagem (Figura 9 e 10).

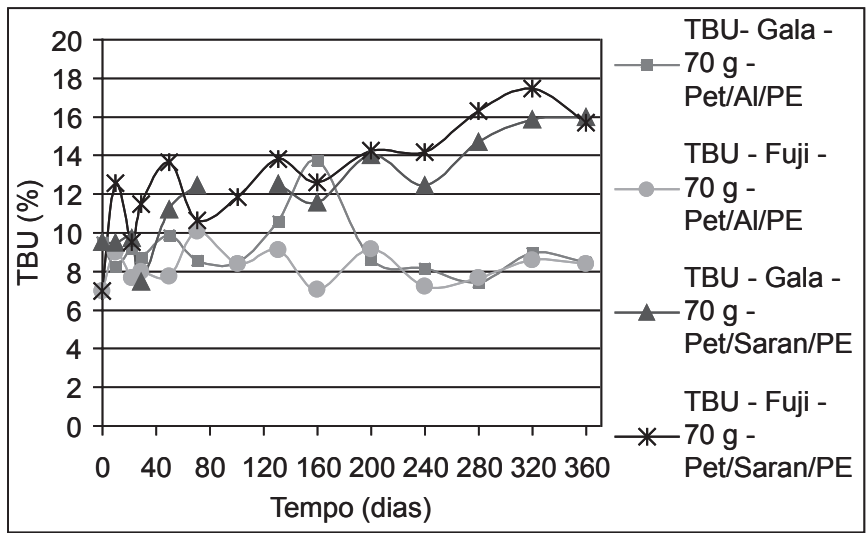

FIGURA 9 - Teor de umidade em base úmida (\%) ao longo do tempo de armazenamento de fatias de maçãs Fuji e Gala desidratadas embaladas em Pet/Al/PE e Pet Saran/PE de 70 g.

As embalagens de Pet/Al/Pe são as embalagens com maior barreira quanto ao ganho de umidade, seguida das embalagens de $\mathrm{PP} / \mathrm{Al} / \mathrm{Pe}$, como se pode observar na Figura 10 , pois as embalagens metalizadas têm por finalidade básica melhorar as propriedades de barreira dos substratos aos quais é aplicada, além de conferir aparência metálica e brilho. Deste modo, por exemplo, um filme de poliéster - PET - pode ter sua taxa de permeabilidade ao oxigênio reduzida de 50 a 100 vezes e sua taxa de permeabilidade ao vapor de água de 20 a 60 vezes, ao ser adequadamente metalizado. As propriedades de barreira de um filme metalizado dependem da natureza do substrato e da quantidade de alumínio depositada (espessura da camada de metalização). O PET foi o primeiro metalizado a ser usado na confecção de laminados de alta barreira, é o que apresenta melhor desempenho e, por isso, tem sua utilização difundida, conforme observado por Garcia et al. [5].

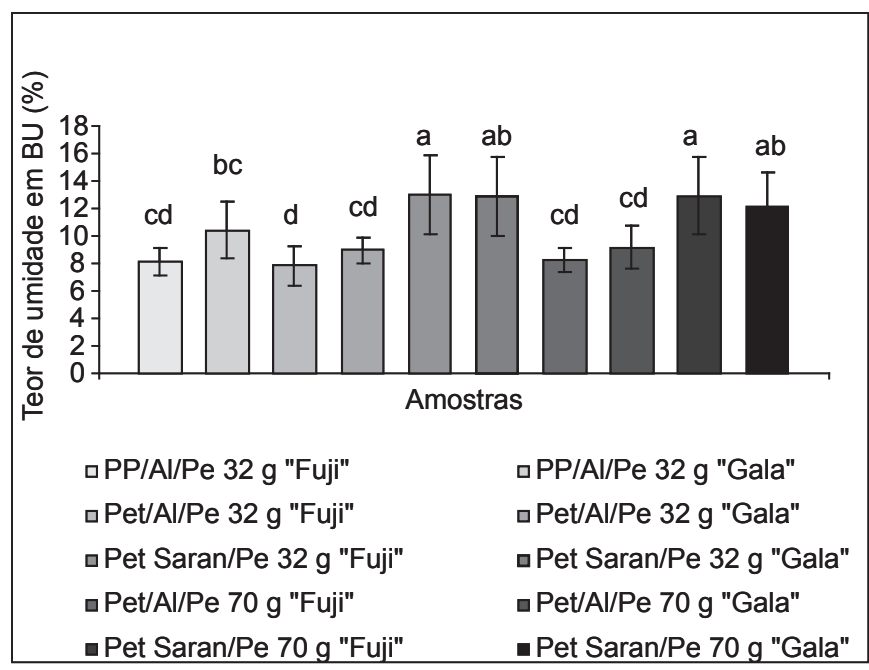

FIGURA 10 - Média do teor de umidade com desvio padrão para as embalagens de Polietileno Tereftalato e Copolímero de Cloreto de Vinil e Vinilideno/ Polietileno (Pet Saran/Pe); de Polietileno Tereftalato/ Alumínio/ Polietileno (Pet/Al/Pe) e Polipropileno/ Alumínio/ Polietileno (PP/Al/Pe). 


\section{4 - CONCLUSÓES}

Por meio da análise sensorial realizada, foi determinado que a cultivar Fuji sem pré-tratamento obteve a maior aceitação dentre os 100 provadores. O pré-tratamento só foi aprovado para a cultivar Gala, e esta ficou em segundo lugar na classificação de aceitação das fatias desidratadas com $79 \%$ de aprovação. O último lugar ficou para as fatias desidratadas de maçãs Gala sem pré-tratamento, obtendo um índice de reprovação de $25 \%$.

Em 360 dias, o ganho de umidade das cultivares Fuji e Gala, foi maior para o armazenamento em embalagens de Pet Saran/Pe, justamente por estas embalagens apresentarem um valor de permeabilidade ao vapor de água 370 vezes maior que o valor para as embalagens de $\mathrm{Pet} / \mathrm{Al} / \mathrm{Pe}$ e PP/Al/Pe. Não se observaram diferenças significativas de ganho de umidade para os dois tamanhos distintos de embalagens, pois a massa de maçã desidratada é proporcional ao tamanho das embalagens, tem-se o dobro de massa de maçã para o dobro de tamanho da embalagem.

As embalagens Pet/Al/Pe e PP/Al/Pe mostraram-se satisfatórias quanto à permeabilidade ao vapor d'água. Estas não apresentaram diferenças significativas entre as mesmas embalagens, quanto ao tamanho e quanto ao armazenamento de cultivares diferentes, sendo recomendadas para armazenamento de maçãs desidratadas.

\section{5 - REFERÊNCIAS BIBLIOGRÁFICAS}

[1] AlveS, R. M. V.; BORDIN, M. R.; GARCIA, E. E. C. Aplicação de um modelo matemático na estimativa da vida-de-prateleira de biscoitos "cream cracker". Colet. ITAL, Campinas, v. 26, n. 1, p. 89-101, jan./jun, 1996.

[2] CABRAL, A. C. D.; ALVIM, D. D. Alimentos desidratadosconceitos básicos para sua embalagem e conservação. Bol. ITAL. Campinas, v. 18, n. 1, p. 1-65, jan./mar, 1981.

[3] DE MELLO, L. M. R.; JÚNIOR, L. B. Mercado Nacional e Internacional. Maçã: pós-colheita. Bento Gonçalves: EMBRAPA, 2004.
[4] EBERT, A. Colheita e armazenagem. Manual da Cultura da Macieira, Empresa Catarinense de Pesquisa Agropecuária, Florianópolis, cap. 20, p. 493-520, 1986.

[5] GARCIA, E. E. C.; PADULA, M.; DANTAS, S. T.; GARCIA, A. E. Materiais Flexíveis metalizados para embalagem. II. Características de permeabilidade ao oxigênio, vapor d'água e transmissão de luz de filmes e laminados. Col. ITAL. Campinas, v. 16, p. 151-182, 1986.

[6] GIRARD, C. L.; NACHTIGALL, G. R; PARUSSOLO, A. Fatores pré-colheita que interferem na qualidade da fruta. Maçã: pós-colheita. Bento Gonçalves: EMBRAPA, 2004.

[7] MEIlgaARD, M; CIVILle, G. V., CARR, B. T. Sensory evaluation techniques. $3^{\circ}$ ed. New York, Ed. crc press, 1999.

[8] Normas Analíticas do Instituto Adolfo Lutz. Vol. 1. Métodos Químicos e Físicos para Análise de Alimentos. 3. ed. São Paulo: Instituto Adolfo Lutz, 1985.

[9] PADUlA, M.; OLIVEIRA, L. M. de. Embalagem para alimentos desidratados. Campinas: ITAL, 1986.

[10] TRAVAGLiNI, D. A; AGUIRRE, J. M.; SILVEIRA, E. F. Processamento de alimentos desidratados. In. Curso de alimentos desidratados. Campinas: ITAL, 1981.

[11] TREPTOW, R. O., QUEIROZ, M. I., ANTUNES, P. L. Preferência e Aceitação de Fatias Desidratadas de Maçãs (Malus domestica Borkh). Revista Brasileira de Agrociência. v. 4, n. 1, p. 41-46, 1998.

[12] TEIXEIRA, E.; MEINERT, E. M.; BARBETTA, P. A. Análise sensorial de alimentos. Florianópolis: Editora da UFSC, 1987.

[13] VICENZI, R.; BILHAUVA, A. B.; TREPTOW, R. de O. Avaliação Sensorial do suco de maçã processado com casca de arroz como coadjuvante de prensagem. Revista Ciência e Tecnologia de Alimentos. Campinas, v. 21 , n. 3, p. 257-261, 2001.

\section{6 - AGRADECIMENTOS}

Ao FUNCITEC e PIBIC/CNPq pelo financiamento e à empresa Lamipack pelo fornecimento das embalagens. 